\title{
Millimole per Liter
}

National Cancer Institute

\section{Source}

National Cancer Institute. Millimole per Liter. NCI Thesaurus. Code C64387.

A unit of concentration (molarity unit) equal to one thousandth of a mole (10E-3 mole) of solute per one liter of solution. 